\title{
Multi-Lifespan Information System Design
}

\author{
Batya Friedman \\ Information School \\ University of Washington \\ Seattle, United States \\ batya@uw.edu
}

\author{
Lisa P. Nathan \\ School of Library, Archival and \\ Info Studies \\ University of British Columbia \\ Vancouver, Canada \\ lisa.nathan@ubc.ca
}

\author{
Daisy Yoo \\ Information School \\ University of Washington \\ Seattle, United States \\ dyoo@uw.edu
}

\begin{abstract}
Contemporary information ecosystems evolve at lightening speed. Last year's cutting edge innovations are this year's standard fare and next year's relics. An information innovation can be implemented, made available through the Internet, and appropriated within 24 hours. Yet, significant societal problems engage much longer timeframes. In 2010 Friedman and Nathan pointed to a fundamental disconnect between mainstream design thinking and these longer-term problems. To address this disconnect, they proposed a multi-lifespan information system design framing.

This workshop builds on previous work by the organizers and others to: (1) elaborate and identify new opportunities and challenges in taking up multi-lifespan information system design problems, and (2) generate critical and constructive discussions for further development of multilifespan information system design thinking.
\end{abstract}

\section{Author Keywords}

Multi-lifespan information system design, design methods, design research, design theory, design thinking.

\section{ACM Classification Keywords}

K.4.2 [Computing Milieux]: Computers and Society--Social Issues; H.5.2 [Information Interfaces and Presentation]: User Interfaces---theory and methods.

\section{DESCRIPTION}

Contemporary information ecosystems evolve at lightening speed. Last year's cutting edge innovations are this year's standard fare and next year's relics. An information innovation can be implemented, made available through the Internet, and appropriated within 24 hours.

Yet, as Friedman and Nathan observed in 2010, some significant societal problems are on much longer timeframes. They wrote: "Genocide. HIV/AIDS. Famine. Deforestation. Habitat destruction. Species extinction. Forced exodus. These problems share some commonalities. In one way or another, they entail widespread losses to human beings, to other sentient beings,

Copyright $(\mathrm{C} 2015$ is held by the author(s). Publication rights licensed to Aarhus University and ACM

5th Decennial Aarhus Conference on Critical Alternatives

August 17-21, 2015, Aarhus Denmark

DOI: http://dx.doi.org/10.7146/aahcc.v1i1.21396 or to the natural world; moreover, those losses are not likely to be made up within the time frame of a single human lifespan (if ever)" ([3], p. 2243). Specifically, they identified three categories of multi-lifespan problems as follows.

\section{Category 1: Limitations of the Human Psyche}

There are some harms that human beings commit against each other that are so profound that while one hopes for healing to occur within a single lifespan, given the human psyche that seems unrealistic. Consider the harms that result from civil war, genocide, and other forms of extreme conflict. When neighbors have killed neighbors, when parents have watched their children die, it may be impossible for persons who have survived to fully heal and forgive those whom they believe guilty of atrocities.

\section{Category 2: Tears in the Social Fabric}

Societies are comprised of complex social structures with deep, intertwined interdependencies - what one might refer to as the "social fabric" through which people care for themselves and each other, pass along generational knowledge, and sustain human life. Certain events - of either a natural or human origin can cause severe tears in the social fabric. Rebuilding societal structures around such widespread changes in population distribution requires time for both the changes to stabilize and the population to regenerate itself.

Category 3: Natural Time-scales that Move More Slowly Than a Single Human Lifespan

Some natural processes can take hundreds of years, for instance the re-establishment of an old growth forest or the revival of an endangered species with long gestation periods and few young. Many environmental crises may benefit from information intensive tools (e.g., climate change simulations) as the solutions unfold over longer time frames.

Friedman and Nathan further pointed to a fundamental disconnect between mainstream design thinking and engaging information system design in support of these classes of longer-term problems. To address this disconnect, they proposed a multi-lifespan information system design framing, calling for an alternative approach to design. At that time, five multi-lifespan information 
system design opportunities were identified including (i) preserving knowledge, (ii) supporting social structure and processes, (iii) remembering and forgetting, (iv) trust, security, and privacy, and (v) inclusivity and access; and three challenges including the challenge of (i) shifting conditions, (ii) passing the baton across generations, and (iii) morale.

The initial framing of multi-lifespan information system design was brief, suggestive and untried. Yet even in this abbreviated form, the framing has begun to have an impact. For example, as of this writing the ACM Digital Library reports over 45 citations to the framing. Some of the citations pertain to the disruption of society as can be found in Tomlinson et al.'s [11] work on collapse informatics and Liu, Palen and Giaccardi's [7] work on legacies of crisis events. Some pertain to considerations of environmental sustainability broadly conceived, as can be found in Jacob et al.'s [6] work on environmental time scales, Nathan's [10] work on sustainable information practices, and Heaney's [5] work on the 'forever problem' of nuclear waste as information. Others pertain to the preservation of digital heritage writ large as can be found in Duranti's [2] work on cultural heritage, Bainbridge's [1] work on the demise of digital worlds, and Garaba's [4] work on preserving liberation struggle heritage. And still others pertain to an individual's end-of-life, as with Odom et al.'s [13] work on digital inheritance, and Moncur and Kirk's [12] work on digital memorials. We also note the organizers' $[8,9,14]$ work on information systems in support of transitional justice. That the multi-lifespan information system design framing has hit a chord with the computing and information research community is evident from both the number of researchers who draw on this framing as well as the diversity of domains and ways in which they do so. At the same time, they bring to light numerous open questions, new opportunities and challenges to further the multi-lifespan information system design endeavor.

This workshop builds on previous work by the organizers and others. In the workshop, we will draw on the organizers' background and participants' experiences to: (1) elaborate and identify new opportunities and challenges in taking up multi-lifespan information system design problems, and (2) generate critical and constructive discussions for further development of the multi-lifespan information system design thinking.

\section{WORKSHOP GOALS}

Toward developing a multi-lifespan information system design approach, the workshop has four goals as follows:

- To explore the distinct attributes of multi-lifespan problems.

- $\quad$ To provide a forum (opportunity) for articulating issues of engaging "(very long) time" frames in designing computer and information systems which have arisen from the participants' own experiences.

- To identify: (a) opportunities and challenges in taking up multi-lifespan information system design problems, and (b) methods that facilitate multi-lifespan design thinking.

- To generate constructive and critical discussions for further development of the multi-lifespan information system design framing and approach.

\section{WORKSHOP FORMAT}

\subsection{Workshop Plan}

Note: Prior to the workshop, participants will have suggested multi-lifespan information system design case studies. Participants' case studies will form the basis of the group discussion after the morning break.

We propose a preliminary agenda and schedule for the 1 full-day workshop as follows:

Welcome and Participant Introductions. (30 min.) Participants are welcomed to the workshop. Participants state why they have chosen to participate in the workshop and what they hope to gain from the workshop experience.

Multi-lifespan Information System Design Concepts and Examples. (1 hour) Explicate and discuss the framing of multi-lifespan information system design, and the particular nature of multi-lifespan problems. Provide illustrative examples. Key questions: What are key attributes across the diversity of multi-lifespan problems? How do we know a multi-lifespan problem when we see one? How does a multi-lifespan problem differ from problems that suggest shorter-term solutions?

Break. (30 min.)

Group Discussion. (1.5 hour) Break out session into groups of 4-5 participants. Discuss the design cases relevant to multi-lifespan information system design prepared by participants prior to the workshop. Elaborate on those cases. Begin to identify common threads on three dimensions: opportunities, challenges, and methods. Reconvene, with brief reports from each group back to the whole. Key questions: What common opportunities and challenges arise from the cases? What are the characteristics of successful methods employed in the cases that are relevant to long(er)term design thinking? What are the characteristics of less successful methods? How do the cases help us to better understand multi-lifespan information system design?

Lunch. (1 hour) Informal discussion continues.

Critique. (1.5 hours) Expand on the morning's discussion of key characteristics of multi-lifespan problems, common opportunities and challenges, and design methods. Generate constructive and critical discussions for further development of the multi-lifespan information system design framing and approach. Key questions: What design 
principles (if any) can we extract from the examples and cases we have studied? What can be done in our design practice to become more responsive to multi-lifespan problems?

Break. (30 min.)

Consolidation. (45 min.) Consolidate discussions.

Wrap-up. (45 min.) Discuss dissemination of the workshop results and future directions. Key questions: How might workshop participants make use of the workshop results in their own work? How might we communicate the results of the workshops to others (e.g., blog, publication in other newsletters)?

\subsection{Method of Interaction}

Based on the organizers' past experience with leading ACM conference workshops (e.g., CHI, DIS, CSCW), high participant engagement emerges when participants feel welcomed, intellectually challenged, and their contributions are valued. The workshop organizers' role is largely of facilitator-ensuring participants have access to the conversation, curbing dominant participants should there be any, and keeping the discussion on track. Participants will be encouraged to lead some of the discussions, to act as scribes, and to otherwise help manage the flow of discussion.

\subsection{Pre-Workshop Activity}

As noted above, participants will be asked to provide brief case studies of multi-lifespan information system design based on their research or personal experiences. Descriptions of these case studies may be distributed to all participants prior to the workshop. Through this reflective process, participants will be well positioned to begin the workshop discussions. Past experience indicates that for complex topics such as the one proposed here, initial work is best achieved through face-to-face interactions.

\subsection{Dissemination of Results}

The first dissemination goal will be to help participants take meaningful results back to their research teams and organizations as well as to encourage participants to discuss the workshop with colleagues. During the course of the workshop, participants and workshop organizers will coconstruct the best ways to achieve this dissemination goal. Secondly and more formally, workshop results will be disseminated through a report published in the Aarhus 2015 Proceedings vol 2. Additional means of dissemination will be solicited and encouraged from workshop participants (e.g., special issue of TOCHI, edited volume).

\section{ORGANIZERS' BACKGROUNDS}

Batya Friedman is a professor in the Information School, adjunct professor in the Department of Computer Science, and adjunct professor in the Department of HumanCentered Design and Engineering at the University of Washington where she co-directs the Value Sensitive Design Research Lab and co-directs the UW Tech Policy Lab. Dr. Friedman pioneered value sensitive design (VSD), an approach to account for human values in the design of information systems. First developed in human-computer interaction, VSD has since been used in information management, human-robotic interaction, computer security, civil engineering, applied philosophy, and land use and transportation. Dr. Friedman is currently working on multilifespan information system design and on methods for envisioning - imagining new ideas for leveraging information systems to shape our futures. Voices from the Rwanda Tribunal is an early project in this multi-lifespan information system design program. In 2012 Batya Friedman received the ACM-SIGCHI Social Impact Award and the University Faculty Lecturer award at the University of Washington. She received both her B.A. and Ph.D. from the University of California at Berkeley.

Lisa P. Nathan is an Assistant Professor and Coordinator of the First Nations Curriculum Concentration at the University of British Columbia's iSchool in Vancouver, Canada. Dr. Nathan directs the Sustaining Information Practice Research and Design Studio. Through a series of projects her team is developing the concept of sustaining information practices, ways of managing information that help diverse peoples address longer-term challenges (e.g., environmental adaptation, decolonization, social justice). Her work has been supported by numerous funders, including the Social Science and Humanities Research Council of Canada (SSHRC) and the U. S. National Science Foundation (NSF). She is currently the chair of the ACMSIGCHI HCI \& Sustainability Community. Dr. Nathan completed her Ph.D. at the University of Washington, USA.

Daisy Yoo is $\mathrm{PhD}$ candidate in the Information School and a member of the Value Sensitive Design Research Lab at the University of Washington. From 2011 to present, Ms. Yoo continues to work as the lead $\mathrm{PhD}$ student on the Voices from the Rwanda Tribunal project to investigate multilifespan information system design. Her work spans the fields of interaction design, human-computer interaction, and information science. Prior to University of Washington, she received her Master's in Interaction Design from Carnegie Mellon University.

\section{A CALL FOR PARTICIPANTS - DRAFT}

Genocide. HIV/AIDS. Famine. Deforestation. Forced exodus. These problems share some commonalities. In one way or another, they entail widespread losses to human beings, to other sentient beings, or to the natural world; moreover, those losses are not likely to be made up within the time frame of a single human lifespan (if ever). It is also the case that information and the interactive processes around information may have much to contribute to the solutions of these problems. How then might we explicitly address this class of problems through information system design? What unique opportunities exist for interactive information systems? What rigorous design knowledge and methods are needed to make progress? In a field known for cutting edge innovation, where devices over five years old 
are regarded as legacy, how can we consider processes and solutions that likely extend beyond a single human lifespan? These questions lay out critical considerations for multi-lifespan information system design.

In this workshop we draw on the organizers' background and participants' research and personal experiences in encountering significant societal issues that will unfold over very long periods of time. Our aims are twofold: (1) to elaborate and identify new opportunities and challenges for taking up multi-lifespan information system design problems, and (2) to generate critical and constructive discussions for further development of multi-lifespan information system design thinking..

Who should attend? Participants with diverse backgrounds are desired including researchers, practitioners, designers, and educators. Interested individuals should submit a 1-3 page position paper by May 15, 2015 describing her or his (1) interest in the topic; (2) one or two cases in which she or he encountered issues of "(very long) time" with regard to information, either as a designer or based on her or his personal experience; and (3) short bio.

\section{PARTICIPANT SOLICITATION AND SELECTION}

We expect 15-25 participants in this workshop. In addition to putting up a website for the workshop, we will also distribute a call for participation on relevant mailing lists (e.g., ACM-SIGCHI mailing and discussion lists). Interested individuals will be asked to submit a position paper that states her or his interest in the topic, one or two relevant cases, and a short bio (see participant call above for details). In the position paper, individuals will be asked to submit descriptions of one or two cases in which she or he encountered issues of "(very long) time" with regard to information, either as a designer or as a person. Each case should discuss the context of the multi-lifespan problem, the information at stake, and the design opportunities and challenges that arose or are anticipated to arise. Participants with diverse backgrounds and design experiences are desired including researchers, practitioners, designers, and educators. Participants will be selected to include a diversity of perspectives in the group as a whole.

\section{REFERENCES}

1. Bainbridge, W. S. (2014). Death of digital worlds. In Digital Death: Mortality and Beyond in the Digital Age, C. M. Moreman and A. D. Lewis Eds. (pp. 215232). Praeger, Santa Barbara.

2. Duranti, L. (2012). Records in the cloud: Towards InterPARES-Trust. Available at: http://93.63.166.138:8080/dspace/handle/2012/97

3. Friedman, B., and Nathan, L. P. (2010). Multi-lifespan information system design: A research initiative for the HCI community. In Proceedings of CHI 2010, ACM Press (2010), 2243-2246.

4. Garaba, F. (2012). Availing the liberation struggle heritage to the public: some reflections on the use of
Web 2.0 technologies in archives within the East and Southern Africa Regional Branch of the International Council on Archives (ESARBICA). Information Development 28(1), 22-31.

5. Heaney, C. (2013). The 'forever problem': Nuclear waste as information. In Proceedings of iConference 2013, ACM Press (2013), 659-661.

6. Jacobs, R., Benford, S., Selby, M., Golembewski, M., Price, D., and Gianniaci, G. (2013). A conversation between trees: what data feels like in the forest. In Proceedings of CHI 2013, ACM Press (2013), 129138.

7. Liu, S., Palen, L., and Giaccardi, E. (2011). Heritage matters in crisis informatics: how information and communication technologies can support legacies of crisis events (pp. 65-86). In Crisis Information Management: Communication and Technologies, C. Hagar, Ed. Oxford, England, Chandos Publishing.

8. Nathan, L.P., and Friedman, B. Interacting with policy in a political world: reflections from the Voices from the Rwanda Tribunal project. interactions 17, 5 (2010), 56-59.

9. Nathan, L.P., Grey, N.C., Lake, M., Nilsen, T., Utter, E., Utter, R.F., Ring, M., Kahn, Z., and Friedman, B. Multilifespan information system design: investigating a new design approach in Rwanda. In Proc. iConference 2011, ACM Press (2011), 591-597.

10. Nathan, L. P. (2012). Sustainable information practice: an ethnographic investigation. Journal of the Association for Information Science and Technology 63(11), 2254-2268.

11. Tomlinson, B., Blevis, E., Nardi, B., Patterson, D. J., Silberman, M. S., and Pan, Y. (2013). Collapse informatics and practice: theory, method, and design. ACM Transactions on Computer-Human Interaction (TOCHI) 20(4): Article 24.

12. Moncur, W. and Kirk, D. (2014). An emergent framework for digital memorials. In Proceedings of DIS 2014, ACM Press (2014), 965-974.

13. Odom, W., Banks, R., Kirk, D., Harper, R., Lindley, S., and Sellen, A. (2012). Technology heirlooms?: considerations for passing down and inheriting digital materials. In Proceedings of CHI 2012, ACM Press (2012), 337-346.

14. Yoo, D., Lake, M., Nilsen, T., Utter, M.E., Alsdorf, R., Bizimana, T., Nathan, L.P., Ring, M., Utter, E.J., Utter, R.F., and Friedman, B. Envisioning across generations: A multi-lifespan information system for international justice in Rwanda. In Proc. CHI 2013, ACM Press (2013), 2527-2536. 